\title{
An Interchange Heterozygote in Lycopersicon esculentum Mill. and the Movement of Chiasmata over the Non-homologous Segments
}

\author{
K. R. Khanna and R. C. Chaudhary \\ National Botanic Gardens, Lucknow, India
}

Received November 25, 1968

\section{Introduction}

Chromosome interchanges are frequent in plants, occurring both spontaneously as well as under the influence of external agencies. Although the exact mechanism of interchanges remains unknown, their study has been a great aid to plant breeders (Anderson 1935) and has thrown light on many fundamental problems of cytogenetics (Burnham 1956) and evolution of sex chromosomes (Khanna 1964, 1968). Presently we are concerned with the forces of attraction which have been postulated to exist between the homologous chromatids at the time of chiasma terminalization. A translocation heterozygote, depending upon whether or not the chiasmata originating proximally in the homologous segments move over the non-homologous ones, is particularly suited for testing the validity of this argument. A number of studies (see Darlington 1965) have failed to show the movements of chiasmata over the non-homologous segments while several authors have observed configurations in translocation heterozygotes which have been interpreted on the basis of chiasma movement over the non-homologous parts (Marquardt 1948, Hagberg 1954 and Price 1959). The controversy raises an issue in chromosome mechanics, i.e., is the attraction between the homologous chromatids stronger than the repulsion between the homologous chromosomes at the time of chiasma terminalization? This question has been taken up in light of observations on an interchange heterozygote in Lycopersicon esculentum, the arguments of some of the earlier authors have been re-examined and the possibility of movement of chiasmata over the non-homologous segments has been discussed.

\section{Material and methods}

The interchange heterozygote was observed in tomato variety Pusa Ruby. The plant carrying the interchange was a cross between normal and an irradiated individual. The latter was raised from seeds irradiated at $5000 \mathrm{r}$ with gamma rays, after twenty hours in soaked condition. It was distinct from other plants because of its brittle foliage, chlorophyll chimaeras and small flowers with thin petals which, however, turned normal later on. Pollen 
grains were ninety eight to hundred per cent abortive and no fruits were produced on selfing. Crosses with the control resulted in several seeds from which the material of the present study was derived. Morphologically these

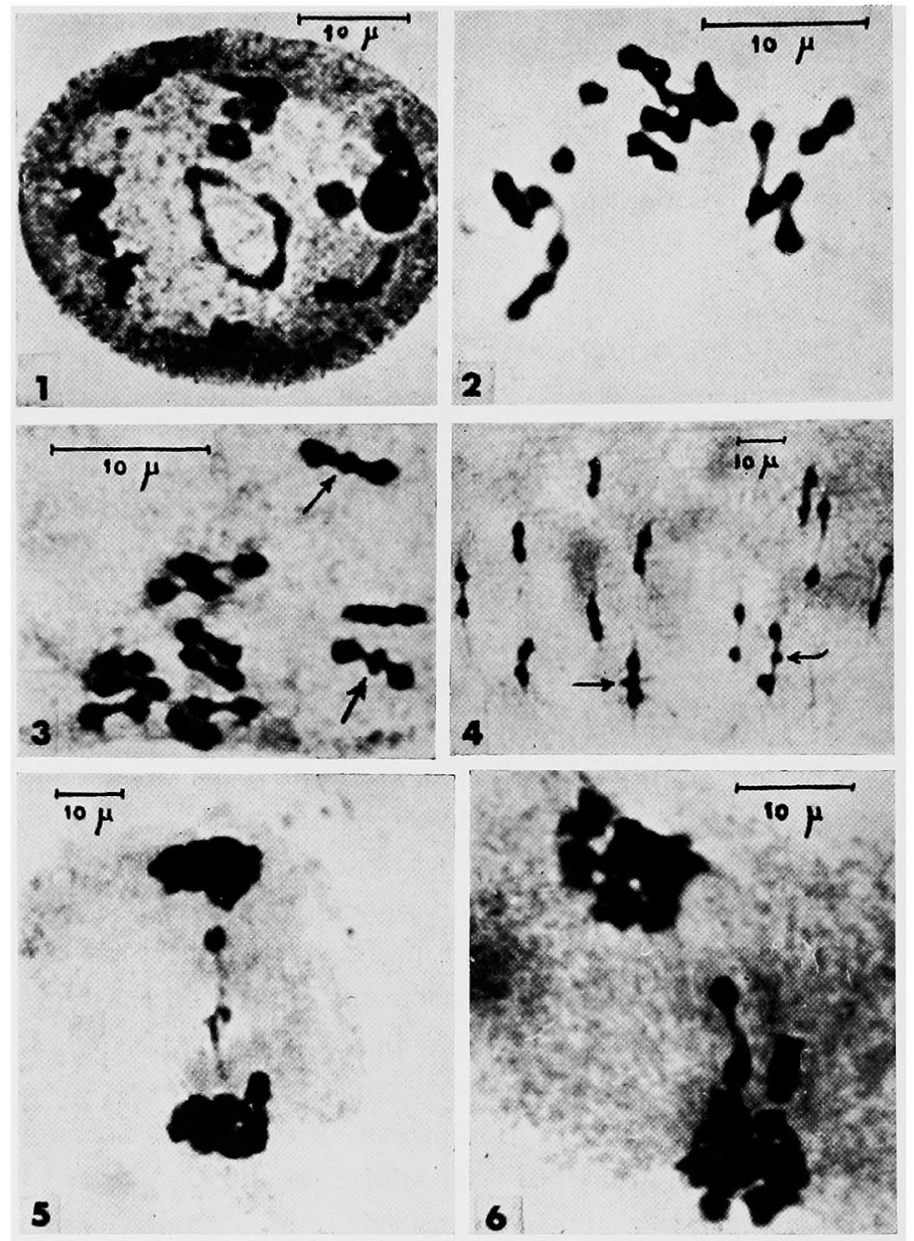

Figs. 1-6. Translocation quadrivalent at: 1, diakinesis. 2, MI. 3 and 4 , the translocation bivalents showing the arrest of chiasmata (arrow marked) at the distal ends. 5 and 6, the division of the fragments at AI. These fragments are due to the non terminalization of chiasmata. plants were not distinguishable from other plants of the variety Pusa Ruby.

The flower buds were fixed in $1: 3$ acetic alcohol and were studied by the usual acetocarmine squash technique. The pollen fertility was also counted by staining with acetocarmine and the stained pollen grains have been taken as fertile.

\section{Results}

The chromosome configurations were analysed at the various stages of meiosis. At diakinesis, as is evident from Table 1 , in 32.8 per cent of the cells a quadrivalent was observed (Fig. 1) while the

Table 1. The various translocation configurations at diakinesis

\begin{tabular}{|c|c|c|c|c|}
\hline & \multirow{2}{*}{$\begin{array}{l}\text { Translocation } \\
\text { bivalents }\end{array}$} & \multicolumn{2}{|c|}{ Translocation } & \multirow{2}{*}{$\begin{array}{l}\text { Quadrivalent of } 4 \text { chain } \\
\text { of } 3 \text { and } 1 \text { univ. }\end{array}$} \\
\hline & & Ring & Chain & \\
\hline $\begin{array}{l}\text { Number of cells in } \\
\text { which observed }\end{array}$ & 96 & 26 & 20 & 1 \\
\hline $\begin{array}{l}\text { Percentage of the } \\
\text { cells examined }\end{array}$ & 67.2 & 18.2 & 13.9 & 0.7 \\
\hline
\end{tabular}


rest 67.2 per cent had bivalents only. Relatively infrequent occurrence of the quadrivalent and its formation into a chain, observed in about half of the cases, is due to short distally translocated segments. Not unexpectedly, therefore, at MI a ring quadrivalent was never observed in our study. The chain of four (rarely a chain of three and one univalent) oriented itself in a zigzag manner (Fig. 2) with the forces of orientation beginning from one end. The disjunction of the quadrivalents is always regular. In the absence of the quadrivalent the behaviour of the bivalents with translocated segments became apparent only after the completion of MI. These bivalents could be distinguished by the non terminalization of chiasmata at the distal ends (Figs. 3 and 4). Apparently, breakage always occurred at these points. The observed frequency of laggards at $\mathrm{AI}$ and that of the fragments at late $\mathrm{AI}$ and $\mathrm{TI}$ are given in Table 2. They show good agreement with each other.

Table 2. The occurrence of laggards and fragments at the end of first meiotic division

\begin{tabular}{l|c|c|c}
\hline \hline Stage of meiosis & $\begin{array}{c}\text { Number of normal } \\
\text { cells }\end{array}$ & $\begin{array}{c}\text { Number of abnormal } \\
\text { cells }\end{array}$ & $\begin{array}{c}\text { Per-centage of } \\
\text { abnormal cells }\end{array}$ \\
\hline AI & 49 & $\begin{array}{c}88 \\
\text { (with laggards) } \\
38\end{array}$ \\
Late AI and TI & 24 & (with fragments) & 64.2 \\
\hline
\end{tabular}

With the completion of AI, the bivalent fragments moved independently towards the poles sometimes both of them going to the same pole (Fig. 6). Occasionally they disjoined irregularly at AI (Fig. 5) and were also observed as laggards at AII.

The pollen fertility counts in the translocation hybrid were taken on 23 rd of January, 28th of February and 15th of March 1967. The fertility counts were recorded as 50,54 and 54 per cent respectively. The pollen fertility in the control, on the other hand, was ninety eight per cent during this period. While about thirty-three per cent fertility in the translocation hybrid is explainable on the basis of regularly disjoining quadrivalents, the rest seventeen to twenty-one per cent fertility must be due to the regular inclusion of the complete bivalent fragment in some of the cells.

\section{Discussion}

The present observation support the lack of movement of chiasmata over the non-homologous segments. The quadrivalents showed complete terminalization of chiasmata without any difficulty because the chiasmata were formed in the distal segments that were homologous. In no case a quadrivalent was observed to show an irregular disjunction. In the cells lacking quadrivalents, i.e., where only bivalents were formed, two bivalents were observed with arrested chiasmata till late MI. Apparently breakage occurred at these points so that two double fragments (rarely two lagging bivalents) 
were the end result. However, this statement can be tested statistically. If this statement were correct then the cells with quadrivalents would be devoid of any fragment or laggards at the completion of the first division of meiosis while the cells with bivalents only would show them. The number of cells with and without fragments and laggards were counted in stages later than MI (Table 2) and $X^{2}$ test (Table 3$)$ shows satisfactory agreement $(\mathrm{P}=0.3-0.2)$ between the observations and the expected results.

Table 3 .

\begin{tabular}{c|c|c|c|c}
\hline \hline $\begin{array}{c}\text { AI and later stages } \\
\text { of meiosis }\end{array}$ & $\begin{array}{c}\text { Probability of } \\
\text { occurrence }\end{array}$ & $\begin{array}{c}\text { No. of cells } \\
\text { observed }\end{array}$ & $X^{2}$ & $\mathrm{P}$ \\
\hline $\begin{array}{c}\text { Cells with fragments } \\
\text { and laggards }\end{array}$ & 0.67 & 126 & 1.10 & $0.30-0.20$ \\
$\begin{array}{c}\text { Cells without fragments } \\
\text { and laggards }\end{array}$ & 0.33 & 73 & \\
\hline
\end{tabular}

In tomato, the chiasmata have been postulated to be of a localized type (Barton 1951). In the present study we find that in the quadrivalent when the pairing is between short distal segments the chiasmata originate there. On the other hand, when the same chromosomes pair as bivalents because of the longer homologous segment, the chiasmata originate proximally to the point of translocation and their terminalization gets arrested as it reaches the non-homologous segment. Even though this change in the position of origin of chiasmata seems to have been brought about by translocation, the chiasmata in tomato should be called of a "semi-localized" type.

The present findings, though in accord with Darlington (1929, 1937), Sansome (1932), Dark (1936) and Darlington and Gairdner (1937) as regards the lack of chiasmata movement over the non-homologous segments, are different from the conclusions of Marquardt (1948), Hagberg (1954) and Price (1959). The studies of Marquardt (1948) on Oenothera and Price (loc. cit) on Secale are somewhat alike because of the similarity of configurations of the translocated chromosomes observed by them. Besides the configurations which can be explained by the terminalization of chiasmata, these authors have observed configurations like the shape of a pan, a figure of eight and some derivatives from these types. These configurations, the above authors believe, can only be explained by the movement of chiasmata over the non-homologous segments. This may not necessarily be the case. Such configurations could have arisen, if the translocation involved chromatids instead of chromosomes. This is represented below in Fig. 7. Chromatid translocations occur frequently in plants though they are not as common as the chromosome translocations. Some notable chromatid translocations in plants are: Paris (Haga 1953) and Tradescantia (Catcheside, Lea and Thoday 1946).

Moreover, Marquardt makes the presumption that the translocation segments are short and distal and therefore the multiple chiasmata met with distally must have originated interstitially and moved over the non-homologous parts 
to reach the distal position. Taking the situation in Oenothera in general, such a presumption seems hardly justified, because the translocations in this case have occurred mostly near the centromere.

Hagberg's studies in which he thinks that the chiasmata move over non-homologous segments are based on two hybrids : 1. Between parents homozygous for translocations between chromosomes $\mathrm{a}$ and $\mathrm{b}$, but breaks occurring at different points $(\operatorname{Trab} \times \operatorname{Tr} 7)$ and

2. Between parents homozygous for translocations between chromosomes $\mathrm{b}$ and $\mathrm{g}$ and $\mathrm{e}$ and $\mathrm{g}$ $(\operatorname{Trbg} \times \operatorname{Tr} 1)$. Because of the unequal size of the chromosomes involved, the heterochromatic bivalents with knob when there are two chiasmata, are of course, expected. The types of knobs formed in the two cases are, however, different. From the photographs given by
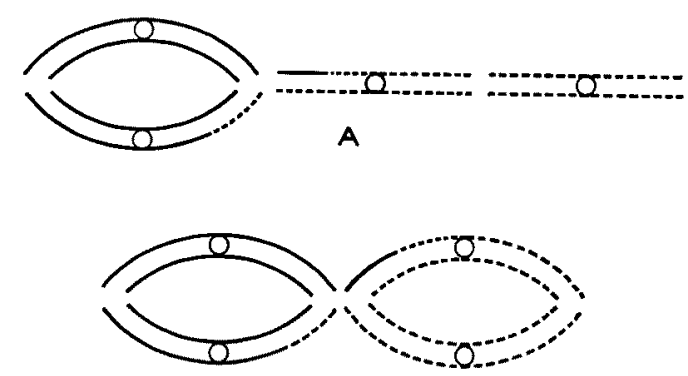

B

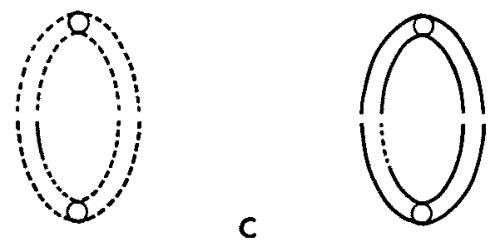

Fig. 7. The configurations of the shape of a pan (A) a figure of eight (B) and two rings (C). Such configurations may be formed as a result of chromatid translocations as is shown by their position and may not necessarily involve the movement of chiasmata over the non-homologous points. Hagberg, it can be clearly seen that in the former the knobs are interstitial (Hagberg's Fig. 4) while in the latter they are terminal (Hagberg's Figs. 11-13). In the first situation the chiasmata may be formed in segments distal to the knobs and the problem of their getting stuck at the non-homologous points may never arise. It is worth noting that no laggards have been reported in translocation hybrids of this type. In the second type, it appears from the photographs, at least, that the chiasmata have not terminalized completely and it is in this type that the laggards have been observed. The observation of laggards is a proof of non-terminalization of chiasmata, a fact remaining unexplained on the basis of the hypothesis suggested by Hagberg.

The reasons for the arrest of the chiasmata at the non-homologous points is the strong attraction between the homologous chromatids. This force of attractions seems to be so strong that even when present in relatively small segments, it may be equal to or greater than the entire force of repulsion existing between the two homologous chromosomes as well as between the two centromeres. This situation is represented in Fig. 8. Normally such a force may not be perceptible because during chiasma terminalization a chromatid changes from one homologous partner to another which would also be attracting it with the same force. 
To sum up, although some configurations have been explained on the basis of the movement of the chiasmata over the non-homologous segments, the evidence is far from conclusive. Unless some definite evidence is brought forth, the established hypothesis of attraction between homologous chromatids

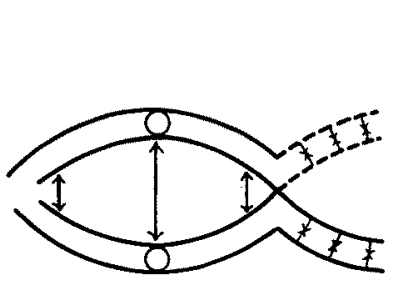

A

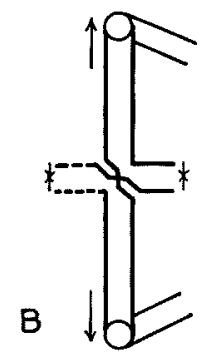

Fig. 8. Diagramatic representation of the translocation bivalent at diakinesis (A) and MI (B). Repulsion is shown by the arrows pointing away from each other while the arrows pointing towards each other indicate attraction. Further explanation in the text. at the time of chiasma terminalization and the arrest of chiasma movement at non-homologous points should stand.

Translocations in tomato have previously been observed by Brown (1949), Gottschalk (1951a, b) and Barton (1951 and 1954). Brown has not discussed translocations after MI. Gottschalk studied only the pachytene material which was not studied in the present case. Barton (1951) observed the translocation configuration to be of a shape of a ring quadrivalent in sixtythree percent cases, a chain of three and a univalent in four percent cases and as pairs of two bivalents in thirty-three percent cases. The frequency of these configurations is almost the reverse of what has been observed in the present material. But in Barton's material the translocations have occurred in close proximity of the centromere involving much longer chromosome arms than is the case in the present material. The difference in the frequency of the two types of configurations in the two material is understandable on the basis of preferential pairing : the longer the translocated segments, the more frequent the quadrivalent formation. In such types of translocations when the interchange is close to the centromere the chiasmata are formed in the homologous segment and the question of their movement over the non-homologous parts or that of fragmentation does not arise. The formation of quadrivalents in Barton's material suggests that the chiasmata are not strictly localized, a conclusion also reached earlier in the present study. The translocations observed by Barton (1954) are of a deficiency type. He observed these translocations between chromosomes one and eight, and two and three. In former it was interstitial and in the latter it was terminal. In our material no configurations like heteromorphic bivalents which may be suggestive of a deficiency translocation were observed.

The fragments, in the present investigation represent the distal chromosome ends and are, therefore, primarily euchromatic. In this respect they are similar to the fragments observed by Barton (1954) which have also originated as a result of translocation and represent the distal euchromatic ends. However, the behaviour of these fragments in two cases is quite different. In the 
present case the fragments persisted from the time of their origin till as late as telophase II and although they tend to become diffused during the later stages of meiosis, no diminution in size occurred. In Barton's material, the fragments under went extreme reduction in size, almost to the point of microscopic resolution. This difference in the two materials remains unexplained.

\section{Acknowledgments}

The authors are grateful to Dr. L. B. Singh, Director, National Botanic Gardens, Lucknow for his keen interest in this study.

\section{Summary}

Translocation configurations have been studied in a structural heterozygote in Lycopersicon esculentum Mill. The quadrivalents and bivalents have been observed with a frequency of 32.8 and 67.2 percent respectively. The quadrivalents behave normally while the bivalents lag at AI because of the lack of movement of chiasmata over the non-homologous segments. This leads to meiotic abnormalities, like fragmentation, observable at $\mathrm{AI}$ and subsequent stages. Previously known cases of this nature have been reviewed and it has been suggested that the reported exceptions to this general rule may be explained on the basis of chromatid instead of chromosome translocations.

\section{References}

Anderson, E. G. 1935. Chromosomal interchanges in maize. Genetics 20: 70-83.

Barton, D. W. 1951. Localized chiasmata in the differentiated chromosome of the tomato. Genetics 36: $374-381$.

- 1954. Comparative effects of X-ray and ultra-violet radiation on differentiated chromosome of the tomato. Cytologia 19: 157-175.

Brown, S. K. 1949. The structure and meiotic behaviour of the differentiated arm of the tomato chromosome. Genetics 34: 437-461.

Burnham, C. R. 1956. Chromosomal interchanges in plants. Bot. Rev. 22: 419-552.

Catcheside, D. G., Lea, D. E. and Thoday, J. M. 1946. Types of chromosome structural changes induced by the irradiation of Tradescantia microspores. J. Genet. 47: 113136.

Dark, S. O. S. 1936. Meiosis in diploid and tetraploid Paeonia species. J. Genet. 32: 353372.

Darlington, C. D. 1929. Meiosis in polyploids. J. Genet. 21: 17-56.

- 1931. The cytological theory of inheritance in Oenothera. J. Genet. 24: 405-474.

- 1965. Cytology, London.

- and Gairdner, A. E. 1937. The variation system in Campanula persicola. J. Genet. 35: $97-128$.

Gottschalk, W. 1951a. Untersuchungen am Pachyten normaler und röntgenbestrahlter Pollenmutterzellen von Solanum lycopersicum. Chromosoma 4: 298-341.

- 1951b. Der Vergleich von röntgen und chemisch induzierten Chromosomenmutationen in Pachyten von Solanum lycopersicum. Chromosoma 4: 342-358.

Haga, T. 1953. Meiosis in Paris II. Spontaneous breakage and fusion of chromosomes. Cytologia 18: 50-66. 
Hagberg, A. 1954. Cytogenetic analysis of erectoides mutations in barley. Acta. Agr. Scand. 4: $472-490$.

Khanna, K. R. 1964. Evolutionary significance of heterochromatic translocations in monoecious Grimmias. Am. J. Bot. 51: 672 .

- 1968. Evolution of sex chromosomes in Bryophytes. Recent advances in Bryology (in press).

Marquardt, H. 1948. Das Verhalten röntgeninduzierter Viererringemitgrossen interstitiellen Segmenten bei Oenothera Hookeri. Z. Ind. Abst. Vererb. 82: 415-429.

Price, S. 1959. Chiasma terminalization in a structural heterozygote in Secale. Genetics 44: 705-712.

Sansome, E. R. 1932. Segmental interchanges in Pisum sativum. Cytologia 3: 200-219. 